\title{
Cervical cancer screening and registration-are they working?
}

\author{
Andrew Choyce, Brian R McAvoy
}

\begin{abstract}
Study objective-The aim of the study was to investigate the accuracy of one year's cervical cancer registrations and to review these women's medical records.

Design-The study was a survey of medical records of women registered as having a malignancy of cervix or uterus in 1985.
\end{abstract}

Setting-Cases were drawn solely from the county of Leicestershire, having been registered by the Trent Cancer Registration Bureau.

Patients-The study group comprised all 82 women registered as having a malignancy of cervix or uterus (part unspecified) during the study period. In one case the medical records could not be obtained, so 81 were reviewed.

Measurements and results-Medical records were reviewed; demographic, clinical and tumour characteristics, and screening experience were noted. Errors of registration of invasive cancer resulted in a $22 \%$ overestimate: only 54 of 66 cases registered actually had this cancer. Cases over 40 years of age $(n=37)$ were compared to those under $40(n=17)$. Thirty two women $(59 \%)$, predominantly in the older age group, had never had a cervical smear. Forty four women $(81 \%)$ presented with symptoms rather than as a result of screening. There was no difference in the stage of the disease at presentation between the two age groups but eight of nine women under 35 years had poorly differentiated tumours. At 2 year follow up, 12 (71\%) of the younger women were alive and asymptomatic, one had a recurrence and four were dead. The corresponding figures for the older women were $18(50 \%), 5(14 \%)$ and $13(36 \%)$. Eight screened women had only had normal smears reported in the 5 years preceding the cancer diagnosis. Seven of these were under 45 years old and four had late stage disease.

Conclusions-It will be impossible to assess the impact of newly implemented computerised call and recall systems for cervical cytology screening unless a more reliable data base can be created.

LE2 $7 \mathbf{L X}$

B R McAvoy

Correspondence to: Professor McAvoy at Department of General Practice, School of Medicine, University of Auckland, New Zealand

Accepted for publication July 1989
International studies have shown that mort from cervical cancer has fallen most in those countries or regions which have introduced comprehensive screening programmes. ${ }^{1-7}$ The latest Health Circular from the Department of Health and Social Security states that "the objective of the cervical screening programme is to reduce mortality from cervical cancer by regularly screening all women at risk in order to identify and treat conditions that might otherwise develop into cancer". 8 It is hoped that the programme will reduce the incidence of cervical cancer, which currently kills over 2000 women annually in England and Wales. We studied a group of Leicestershire women registered as having invasive cervical cancer to ascertain how effective our local programme had been.

\section{Methods}

Details of all Leicestershire women registered in 1985 as having a malignant neoplasm of the cervix uteri or uterus (part unspecified), ie, International Classification of Disease (ICD) codes 180 and 179 respectively, ${ }^{9}$ were obtained from the Trent Cancer Registration Bureau. With the cooperation of the Division of Obstetrics and Gynaecology, the Medical Records Department, Radiotherapy Department, and Cytology Laboratory at Leicester Royal Infirmary, the medical records of all women except one were obtained and reviewed. Demographic, clinical and tumour characteristics and screening experience were noted in each case.

\section{Results}

Of the 81 patients studied, the diagnosis of invasive cervical cancer was confirmed in 54 . Sixty-six women were registered as ICD 180 , in whom the diagnosis of invasive cervical cancer was confirmed in only 53. The remaining registrations were found to consist of 10 cases of carcinoma in situ, one of endometrial carcinoma and one woman who had been registered in an earlier year. One set of notes proved untraceable. The final confirmed case of cervical cancer was one of the 15 women registered as ICD 179. The most recently available quinquennial figures (1979-83) for Leicestershire show an annual incidence rate of 14.6 per 100000 women for invasive cervical cancer. ${ }^{10}$

The age distribution of the 54 patients was bimodal (figure), 17 (31\%) of women being under 40 years old ("younger" group) and $37(69 \%$ ) over 40 ("older" group). Thirty two (59\%) had never had a cervical smear before the diagnosis of invasive cancer. Older women were more than three times more likely not to have had a cervical smear than younger women $(76 \% v 24 \%)$. Forty four $(81 \%)$ presented with symptoms; this figure was similar for both age groups. Diagnostic (ie, 


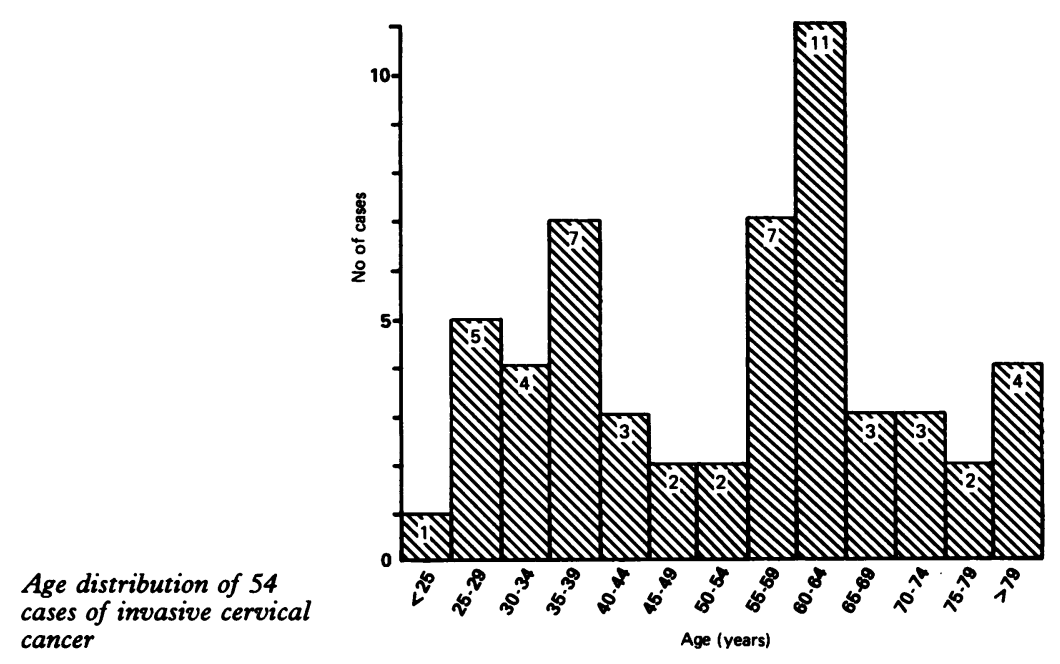

cases of invasive cervical cancer

Detailed smear histories of eight women with cervical cancer who had only normal smears reported in the 5 years preceding registration.

post-symptomatic) smears were performed in 28 $(52 \%)$ of the women.

Ninety four per cent of the tumours were squamous cell carcinomas, the remainder being adenocarcinomas. Tumours were staged using the classification of the International Federation of Gynaecology and Obstetrics, based on clinical examinations with and without anaesthesia. ${ }^{11}$ Early disease is taken to mean stages I and IIA and late disease stages IIB, III and IV. There was no significant difference in the stage of the disease at presentation between the two age groups, seven (41\%) younger and $13(39 \%)$ older women presenting with late stage disease. Of the 42 cases in whom histological diagnosis was available, five $(12 \%)$ had well differentiated tumours, $17(40 \%)$ moderately differentiated and $20(48 \%)$ poorly differentiated. These figures were similar for the older and younger age groups, but in eight of the nine women $(89 \%)$ under 35 whose histology was available, the tumours were poorly differentiated, compared to 12 out of $33(36 \%)$ over $35(p<0.01)$.

Follow up at two years was available for all but one patient. The overall two year survival rate was $68 \%$. Twelve $(71 \%)$ of the younger women were alive and asymptomatic, one $(6 \%)$ had recurrence and four ( $24 \%$ ) were dead; the corresponding figures for the older women were $18(50 \%), 5$ $(14 \%)$ and $13(36 \%)$ respectively. These differences are not statistically significant.

Of the most concern was the group of 22 women who had had at least one cervical smear taken in the five years preceding diagnosis of invasive cervical cancer. Twelve $(55 \%)$ of these women had at least one negative smear and eight $(36 \%)$ had only normal smears reported during this time, three of them within the preceding two years. Details of their smear histories are shown in the table. Of particular concern is the fact that seven of these eight women were aged under 45 and four of these had late stage disease.

\begin{tabular}{lllll}
\hline Age & \multicolumn{2}{l}{ No of smears in previous } & $\begin{array}{l}\text { Date of } \\
\text { last normal } \\
\text { smear }\end{array}$ & $\begin{array}{l}\text { Date of any } \\
\text { abnormal } \\
\text { smear }\end{array}$ \\
\cline { 2 - 5 } & 5 years & 10 years & 1984 & 1979 \\
\hline 23 & 3 & 4 & 1983 & - \\
33 & 2 & 2 & 1983 & - \\
35 & 1 & 1 & 1981 & - \\
38 & 2 & 2 & 1982 & - \\
38 & 1 & 2 & 1982 & - \\
39 & 1 & 2 & 1981 & $1978(2)$ \\
43 & 1 & 3 & 1980 & - \\
62 & 1 & 1 & & \\
\hline
\end{tabular}

\section{Discussion}

Close scrutiny of the case notes belonging to Leicestershire women registered as ICD 180 in 1985 revealed a discrepancy between confirmed invasive cervical lesions and all registered lesions which resulted in a $22 \%$ overestimate of the incidence of this cancer. Potential sources of error in the production of these statistics may arise at several stages in the process of interpretation, classification and coding of cases before they are finally entered onto the Cancer Register. Such work can be undertaken by a variety of clerical staff, some less skilled and experienced than others. As seven different hospitals were involved in this study the potential for errors is further multiplied. Cervical cancer is particularly prone to such coding errors ${ }^{12}$ since registration may be based on a clinical diagnosis, which may not be confirmed or refuted histologically until some time after the patient's discharge. Furthermore, it can be difficult in advanced cases to differentiate clinically between endometrial and cervical cancer. The scale of the discrepancy between registered and confirmed cases revealed in this study raises serious doubts about the validity of such data in the monitoring and assessment of the cervical screening programme. Such errors add to the concerns already expressed about the effect of inaccuracies in death certificates and coding practices in the United Kingdom ${ }^{1314}$ and the European Economic Community on international mortality statistics. ${ }^{12}$

As in previous studies, ${ }^{15-17}$ the age distribution of the patients affected was bimodal. This is consistent with national changes in registration rates which have shown an increase in cases amongst younger women. ${ }^{18}$ Indeed, $19 \%$ of the registrations were in women under 35 years old, compared with $16 \%$ nationally. ${ }^{19}$

Fifty nine per cent of the women had never had a cervical smear, the majority $(88 \%)$ of these being over 40 . The age difference reflects that described in other studies, 161720 but the nonuptake, although high, is lower than that in similar studies in Yorkshire $(82 \%),{ }^{17}$ Cambridgeshire $(72 \%)^{15}$, the North West region $(71 \%),{ }^{16}$ and South West Thames region $(68 \%) .{ }^{20}$ Since these studies involved registrations in the 1970 s and very early 1980 s, perhaps the lower non-uptake of cytology indicates increasing acceptability of the screening programme. Sadly this is unlikely since only $19 \%$ of the women were detected by presymptomatic screening, $81 \%$ presenting with symptoms. Of the postsymptomatic smears only $42 \%$ were reported as showing malignant cells, confirming the unreliability of cervical smears as a diagnostic tool in symptomatic patients. ${ }^{16}$

It has been suggested that in younger women cervical cancer may adopt a more agressive form, but the evidence is conflicting. ${ }^{21}$ In this small series there was no significant difference between the older and younger women in the stage of the disease at presentation, but there were significantly more women under 35 than over 35 with poorly differentiated tumours. There were, however, no significant differences in survival or recurrences at two years between older and younger women.

Recently there has been a suggestion that the incidence of adenocarcinoma of the cervix may be 
increasing amongst younger women. ${ }^{22-24}$ Our findings did not support this view. Six per cent of this series had adenocarcinoma, but all occurred in women aged over 40 .

Thirty six per cent of screened women had only normal smears reported in the five years preceding the diagnosis of cancer, giving rise to a false sense of reassurance. Previous studies $^{15-1725-31}$ have found recent negative smears in $21-60 \%$ of women developing invasive cervical cancer. Possible reasons for this include inadequately taken smears, failure of the cytologist to recognise malignant cells, or a short induction history. Interpreting the significance of such false negative results in these studies is made more difficult because of differing incidences of cervical cancer and differing uptakes of cervical screening in the various countries. Unfortunately we have been unable to discover whether our cases were false negatives or due to short preinvasive histories, because negative smears were discarded by the laboratory after five years due to lack of storage facilities. Since this study the policy has changed to extend the storage period.

In view of these worrying findings from a study of one year's registrations in one county, a more extensive study over a longer time period and covering a larger area is urgently needed. All District Health Authorities were instructed to implement computerised call and recall systems for cervical cytology no later than 31st March $1988 .^{8}$ It will be impossible to assess the impact of this major administrative initiative unless we can create a more reliable data base for cancer registrations.

We thank Dr D C Bouch, Professor M Clarke, Professor R C Fraser, Dr C Jagger, Mr N Naftalin, Dr D C Pinder and Mr I Smith for advice and cooperation, and al members of the Cervical Cytology Working Group for their support.

1 Anderson GH, Boyes DA, Benedet JL, et al. Organisation and results of the cervical cytology serening programme in British Columbia, 1955-85. Br Med $\Im$ 1988; 296: 975-8.

2 Laara E, Day N, Hakama M. Trends in mortality from cervical cancer in the Nordic coutries: association with organised screening programmes. Lancet 1987 ; i: 1247-9.

3 Macgreor JE, Moss S, Parkin DM, Day NE. Cervical cancer screening in North-East Scotland. In: Hakama M, Miller AB, Day NE, eds. Screening for cancer of the uterine cervix. Lyon: International Agency for Research on Cancer, 1986: $25-36$.

4 Geirsson G, Kristiansdottir R, Sigurdsson K, Moss S, Tulinius $\mathrm{H}$. Cervical cancer screening in Iceland: a case control study. In: Hakama M, Miller AB, Day NE, eds. Screening for cancer of the uterine cervix. Lyon: Screening for cancer of the uterine cervix. Lyon: 5 Berrino F, Gatta G, d'Alto M, Crosignani P. Efficacy of screening in preventing invasive cervical cancer: a case
control study in Milan, Italy. In: Hakama $M$, Miller AB, Day NE, eds. Screening for cancer of the uterine cervix. Lyon: International Agency for Research on Cancer, 1986: 111-123.

6 Patterson F, Bjorkholm E, Karnstrom L. Incidence and Patterson F, Bjorkholm E, Karnstrom $\mathrm{L}$. Incidence and
stage distribution in Sweden: the effect of control measures. stage distribution in Sweden: the effect of control measures. In: Magnus K, ed. Trends in can

7 Cramer DW. The role of cervical cytology in the declining morbidity and mortality of cervical cancer. Cancer 1974;34: 2018-27.

8 DHSS. Health Service Management. Cervical cancer screening (HC88)1; HC(FP) (88)2. 1988.

9 WHO. Manual of the international statistical classification of diseases, injuries and causes of death, 9th revision. Geneva: World Health Organization, 1977.

10 Cancer Quinquennial Tables 1979 to 1983 . Trent Regional Health Authority Cancer Registration Bureau, Sheffield, 1987.

11 International Federation of Gynaecology and Obstetrics. Classification and staging of malignant tumours in the
female pelvis. Acta Obstet Gynecol Scand 1971; 50: 1-7.

12 Kelson M, Farebrother M. The effect of inaccuracies in Kelson $M$, Farebrother $M$. The effect of inaccuracies in
death certificates and coding practices in the European Economic Community (EEC) on international cancer mortality statistics. Int $\mathcal{f}$ Epidemiol 1987; 16: 411-4.

13 Medical Services Study Group of the Royal College of Physicians, London 1978. Death certification and epidemiological research. $\mathrm{Br}$ Med f 1978; ii: 1063-5.

14 Busuttil A, Kemp IW, Hearsman MA. The accuracy of medical certificates of cause of death. Health Bull 1981; 39: 146-52.

15 Walker EM, Hare MJ, Cooper P. A retrospective review of cervical cytology in women developing invasive squamous cell carcinoma. Br $\mathcal{f}$ Obstet Gynaecol 1983; 90: 1087-91.

16 Chisholm DK, Haran D. Cases of invasive cervical cancer in the North West in spite of screening. Br f Family Planning 1984; 10: 3-8.

17 Paterson MEL, Peel KR, Joslin CAF. Cervical smear histories of 500 women with invasive cervical cancer in Yorkshire. Br Med f 1984; 289: 896-8.

18 Draper GJ, Cook GA. Changing patterns of cervical cancer rates. $\mathrm{Br}$ Med $\mathcal{f} 1983$; 287: $510-1$.

19 Office of Population Censuses and Surveys. Cancer statistics registrations. Series MB1 No.16. London: HMSO, 1988. registrations. Series MB1 No.16. London: HMSO, 1988.
20 Ellman R, Chamberlain J. Improving the effectiveness of cervical cancer screening. $f R$ Coll Gen Pract 1984; 34: cervical

21 Russell J, Blair V, Hunter RD. Cervical carcinoma: prognosis in younger patients. $\mathrm{Br}$ Med $\mathcal{F} 1987$; 295: 300-3

22 Peters RK, Chao A, Mack RM, Thomas D, Bernstein L, Henderson $B E$. Increased frequency of adenocarcinoma of the uterine cervix in young women in Los Angeles County. I Natl Cancer Inst 1986; 76: 423-8.

23 Schwartz SM, Weiss NS. Increased incidence of adenocarcinoma of the cervix in young women in the United States. Am $₹$ Epidemiol 1986; 124: 1045-7.

24 Chilvers C, Mant D, Pike MC. Cervical adenocarcinoma and oral contraceptives. $\mathrm{Br}$ Med $\mathcal{f}$ 1987; 295: 1446-7.

25 Grundsell H, Johnsson JE, Lindberg LG, et al. Vaginal smear history in patients with invasive cervical carcinoma. smear history in patients with invasive

26 Dunn JE, Schweitzer MPU. The relationship of cervical cytology to the incidence of invasive cervical cancer mortality in Almeda County, California, 1960 to $1974 . \mathrm{Am}^{\prime}$ mortality in Almeda County, Califo

27 Prendiville W, Guillebaud J, Bamford P, Beilby J, Steele SJ. Carcinoma of the cervix with recent normal Papanicolaou tests. Lancet 1980; ii: 853-4.

28 Rylander E. Negative smears in women developing invasive cervical cancer. Acta Obstet Gynecol Scand 1977; 56: 115-8.

29 Holman CM, McCartney AJ, Hyde KL, Armstrong BK Cervical cytology histories of 100 women with invasive carcinoma of the cervix. Med I Aust 1981; 2: 597-8.

30 Berkley AS, Livolsi VA, Schwartz PE. Advanced squamous cell carcinoma of the cervix with recent normal Papanicolaou tests. Lancet 1980; ii: 375-6.

31 Clarke EA, Anderson TW. Implications of cervical dysplasia. Lancet 1980; i: 1420. 